\title{
Intensive Reading with Reading Lists-An Intervention Study
}

\author{
Linda Fälth' ${ }^{1}$, Camilla Nilvius², Eva Anvegård² \\ ${ }^{1}$ Linnaeus University, Växjö, Sweden \\ ${ }^{2}$ Värnamo Municipality, Värnamo, Sweden \\ Email: Linda.falth@Inu.se
}

Received 24 November 2015; accepted 22 December 2015; published 25 December 2015

Copyright (C) 2015 by authors and Scientific Research Publishing Inc.

This work is licensed under the Creative Commons Attribution International License (CC BY).

http://creativecommons.org/licenses/by/4.0/

(c) (i) Open Access

\begin{abstract}
The study aimed to examine how the decoding, for students with decoding difficulties were affected by an intervention with reading lists. A total of 60 students participated in the study, distributed randomly into intervention groups and control groups, one cohort of primary school children and one with junior high school students. Each group included 15 students. The study was conducted as an intervention with with pre- and post-test where the students' decoding ability were tested. The intervention included 20 occasions of 10 minutes training with reading lists by "Wendick model of intensive reading". The study also aimed to investigate how the decoding performance of the students in the intervention appeared depending on the age of the students. Therefore, the study was conducted with students from both primary school and high school. The intervention group in primary school showed increased decoding ability compared to the control group at all tests. The results also showed that the intervention with reading lists had had a good influence on young children's development of decoding. In junior high school, the intervention group increased more, or equal, compared to the control group, and the largest increase for the intervention group was on the pseudoword reading test.
\end{abstract}

\section{Keywords}

Decoding, Intervention Study, Reading Lists, Reading Difficulties

\section{Introduction}

There are several examples of intervention studies in which positive effects on children's reading skills through interventions are identified (Fälth, 2013; Lundberg, Frost, \& Petersen, 1988; Torgesen et al., 2001; Wolff, 2011). International research has shown positive effects of interventions containing training in phonological awareness 
(Ehri et al., 2001). The same result emerges from a study by Torgesen et al. (2001) concerning children with reading disabilities. The intervention consists of intensive one-to-one tuition in two 50-minute sessions five days per week. The intervention includes two different programs: Auditory Discrimination in Depth (ADD) and Embedded Phonics (EP). ADD stimulates phonological awareness in students by relating to phoneme articulation clues, visual objects and subsequently letters. EP entails a meaningful text forming the basis of phonological awareness training. Although the two programs differ, they both give positive results. Torgesen et al. (2001) conclude that the details of the contents of the program may not be as important in themselves as the phonological basis. It is also important that the phonology of intervention programs is linked to the written language and that the programs are systematically conducted and sufficiently intensive. Several intervention studies have also been made in Sweden. One such study, Reading and Fluency Training-RAFT, is conducted by Wolff (2011). Students with reading and writing difficulties are given one-to-one intensive instruction with a specially designed training program for a limited period. The results are positive. The intervention group has improved their phonemic awareness, spelling, reading comprehension and reading speed. The results also show that the positive effect is retained one year after the intervention.

In a longitudinal intervention study by Gustafson, Ferreira and Rönnberg (2007), children in Grades 2 - 3 receive either phonological or orthographic training. There are also two control groups. The first control group contains typical readers and the other students who receive ordinary special education. The results show good effects on reading comprehension and decoding both for those who train phonology and for those who practise orthography, but they are not significantly higher than for the control groups. One observed result is that children with expressed phonological difficulties improve their collateral word decoding better by phonological than by orthographic training. One conclusion to be drawn from this is that measures should focus on children's weakness rather than on their relative strength in decoding. Another Swedish intervention study by Fälth et al. (2013) includes 100 pupils with reading difficulties in Grade 2. The participants are divided into four groups and are subjected to 20 sessions of various computer-based training programs. One group uses a program that trained reading and another program with only phonological exercises. The third group obtains a combination of both reading comprehension and phonological training, while the last group received regular teaching by specialist teachers. One-to-one tuition is used throughout. The study also includes a control group of typical readers. The results show that the intervention group that trains both reading comprehension and phonology achieves significantly better results than the other groups. Fälth et al. (2013) suggest that a possible explanation is that the variation between two different training programs can be motivating in itself, and that this variation may improve the chance that one of the programs may suit the student's specific difficulties.

However, as for training with reading lists, only a few small intervention studies have been made, often as student degree projects and presented as papers, for example within special needs teacher education. In Sweden, these studies were based on 2 different types of word list materials, "Rydaholm” (Pettersson, 2015) and "Bravkod" (Jönsson, 2010). Still, in these studies the number of participants and the frequency of sessions are often low. Egerhag \& Svärd (2011) conducted an intervention study with 15 students in Grade 7 who practised for five weeks with the "Rydaholm" reading lists. Most students in the study increased their decoding ability. In sum, these small intervention studies, using reading lists as a method for developing word decoding, showed positive results in terms of word decoding development among the participant students.

According to Gustafson, Ferreira and Rönnberg (2007), interventions should be intense, systematically structured and preferably concentrated and not spread over an extended period of time. In addition, the National Reading Panel (2000) suggests that intense interventions comprising three sessions per week for three months are more effective than those with one session per week for nine months. As a measure for increasing students' decoding abilities researchers recommend a systematic and explicit instruction in phonological reading with the emphasis on phoneme analysis and phoneme synthesis (National Reading Panel, 2000; SBU, 2014). The National Reading Panel's Research Report (2000) highlighted the importance of phoneme-grapheme correspondence training for students with decoding difficulties. The importance of making syntheses and analyses of phonemes is emphasized, as attested by Swedish research (Wolff, 2011).

There are materials in which the sound method provides the basis of both literacy learning methods and for material in special education contexts. Examples of materials used in these contexts contain training with word lists such as the "Rydaholm method" (Pettersson, 2015), "Bravkod” (Jönsson, 2010), and the "Wendick model of intensive reading” (Wendick, 2015). The materials comprise a number of pages, starting with single letters arranged in three columns (letter knowledge). Then follow similar pages, first with syllables only in three col- 
umns. This is followed by lists of words ranging from short and simple words with phonetic spelling, except for high-frequency short words, to more complex words and word inflections. Working sessions are often short, between 15 and 20 minutes, several times a week. The aim of practising by reading lists is to automate the decoding of letters, individual syllables, and whole words. These lists may contain monosyllabic words, pseudowords, bisyllabic words, frequent small words, single and double consonants, consonant clusters, vowel combinations, word stems and endings, non-phonetic spelling and compound words. Such training necessitates one-to-one tuition.

\section{Aims and Research Questions}

The aim of the study is to examine how reading practice with reading lists from the "Wendick model of intensive reading" material can develop decoding in students with decoding difficulties. The study also aims to examine the relation between the decoding development of reading practice involving reading lists and students' age.

The research questions were:

How can training with reading lists from the "Wendick model of intensive reading” during 20 training sessions of 10 minutes each affect students' decoding development?

What is the impact of training with reading lists from the "Wendick model of intensive reading" on the decoding ability of students in primary school and junior high school?

\section{Method}

The "Wendick model of intensive reading" is described as a structured training material for repeated reading. According to Wendick (2015), the material, which comprises small developmental steps and clear progression, aims at automating basic decoding skills. The material is based on the use of 163 structured reading lists that are divided into three chapters. The first chapter includes phonemes, syllables and pseudowords. The second chapter includes content words and the third words with non-phonetic spelling and words with double consonants. The lists begin with independent phonemes, followed by words of one, two and three syllables. Many of the lists are first provided with reading support, involving syllables in bold print or hyphenized. The material also comprises models to visualize the students' development with the help of so-called "reading ladders" and weekly schedules. The feedback from these models is meant to increase the motivation of the student.

The lists are age-independent and can also be used for multilingual students' decoding training. Wendick (2015) recommends 10 - 15 minutes per reading practice time with the focus on intense and effective training, as well as daily practice during four, six or eight weeks. The training implies that the teacher sits opposite the student and points with a pencil through the first vowel in the word that the pupil is supposed to decode. If the student's decoding is wrong, the teacher keeps pointing the pencil to the word until the student decodes correctly. The lists should be read both vertically and horizontally, and the student must decode all the words listed correctly and fluently before moving on to the next reading list. As the same list will be decoded several times, Wendick (2015) claims that automatization will emerge as the decoding becomes easier and easier.

The selection of lists for each student was made by screening, entailing that the students read out loud to the special needs teacher who assessed their reading strategy. In principle, all students in the intervention groups trained with lists both of pseudowords and real words. After the screening, the lists and, consequently, the training were adjusted to whether the student's strategy was phonological or orthographic. All the students in the experimental group received one-to-one tuition with the "Wendick model of intensive reading" on 20 occasions of 10 minutes each. The training lasted for four weeks with one session per day.

Control group students who were also poor decoders attended regular special education classes during the intervention period and thus received the same education as they would have done even if they had not been included in the study.

\section{Participants}

A total of 135 students were screened in the primary group, of whom 34 students obtained stanine scores between 1 and 3 on the word chain test, which was the criterion for being invited to participate in the study. 30 students participated with their parents' consent and were randomized into two groups $(15+15)$, one experimental and one control group. From primary school were 17 boys and 13 girls included in the study, the average age was 8.6 years. 
At the junior high school, a total of 137 students were screened, 35 of whom obtained stanine scores between 1 and 3 on the word chain test. Randomly, 30 students were selected and asked about participation in the study. They were then randomized into two groups $(15+15)$, one experimental and one control group. From jumior high school were 18 boys and 12 girls included in the study, the average age was 14.9 years.

\section{Materials}

Word recognition. Word recognition was assessed by the word chains test (Jacobson, 2001). The task for the children was to silently read chains of words where the blank space between words had been removed and then mark each word boundary with a pencil. Each chain consists of three semantically unrelated words.

Sight word reading. Participants were asked to read simple words out loud as rapidly as possible for 60 seconds (Jönsson, 2010).

Pseudoword reading. The task is to read as many listed pseudowords as possible in one minute. The words do not exist in reality but are pronounceable. Reading pseudowords is a process considered to be performed mainly via phonological processing. Since the child has never seen the words before, the orthographically direct way cannot be used (Jacobson, Svensson, \& af Trampe, unpublished data).

\section{Result}

In Tables 1-6 below, the results are presented in raw scores for each test, before the intervention, test session 1, and after the intervention, test session 2. First, results from the Primary School Group is reported in one table, followed by a table for the Junior High School Group.

Table 1. Results (M and SD) for Word recognition at two test sessions-Primary School Group.

\begin{tabular}{rrrrr}
\hline & \multicolumn{3}{c}{ Intervention group } & \multicolumn{2}{c}{ Control group } \\
\cline { 2 - 5 } & M & SD & M & SD \\
\hline Test session 1 & 9.6 & 2.1 & 11.4 & 2.6 \\
Test session 2 & 15.1 & 2.9 & 15.6 & 3.4 \\
\hline
\end{tabular}

Table 2. Results (M and SD) for Word recognition at two test sessions—-Junior High School Group.

\begin{tabular}{rccccc}
\hline & \multicolumn{3}{c}{ Intervention group } & \multicolumn{2}{c}{ Control group } \\
\cline { 2 - 6 } & M & SD & M & SD \\
\hline Test session 1 & 20.5 & 5.1 & 19.1 & 3.9 \\
Test session 2 & 23.7 & 5.2 & 22.4 & 4.1 \\
\hline
\end{tabular}

Table 3. Results (M and SD) for Sight word reading at two test sessions-Primary School Group.

\begin{tabular}{rcccc}
\hline & & Intervention group & \multicolumn{2}{c}{ Control group } \\
\cline { 2 - 5 } & M & SD & M & SD \\
\hline Test session 1 & 44.5 & 10.8 & 70.9 & 14.1 \\
Test session 2 & 59.3 & 11.2 & 74.9 & 14.9 \\
\hline
\end{tabular}

Table 4. Results (M and SD) for Sight word reading at two test sessions-Junior High School Group.

\begin{tabular}{rcccc} 
& \multicolumn{2}{c}{ Intervention group } & \multicolumn{3}{c}{ Control group } \\
\cline { 2 - 5 } & M & SD & M & SD \\
\hline Test session 1 & 91.4 & 16.9 & 99.3 & 13 \\
Test session 2 & 100.9 & 14.3 & 103.2 & 13.8 \\
\hline
\end{tabular}


Table 5. Results (M and SD) for Pseudoword reading at two test sessions_-Primary School Group.

\begin{tabular}{rccccc}
\hline & \multicolumn{2}{c}{ Intervention group } & \multicolumn{2}{c}{ Control group } \\
\cline { 2 - 6 } & M & SD & M & SD \\
\hline Test session 1 & 12.2 & 3.4 & 20 & 5.9 \\
Test session 2 & 16.5 & 3.4 & 20.8 & 6.6 \\
\hline
\end{tabular}

Table 6. Results (M and SD) for Pseudoword reading at two test sessions_-Junior High School Group.

\begin{tabular}{rccccc}
\hline & & Intervention group & \multicolumn{2}{c}{ Control group } \\
\cline { 2 - 5 } & M & SD & M & SD \\
\hline Test session 1 & 24.9 & 8.1 & 29.8 & 8.8 \\
Test session 2 & 30.3 & 7.2 & 29.3 & 6.1 \\
\hline
\end{tabular}

In the word recognition test the mean value for students in Grades 2 and 3 was 21 word chains, and for students in grades 7-9 it was 48 word chains (Jacobson, 2001). These mean values can be related to the above values, with students in the intervention group having decoding difficulties and obtaining stanine scores between 1 and 3 , which was, consequently, below the average when the study began.

According to the sight word reading test, a critical value, which the students were supposed to reach, is 84 words for students in Grades 2 and 3 and 110 words for students in Grades 7 - 9 (Jönsson, 2010).

According to the test standards, the mean value for Grades 2 and 3 is 22 words, and for Grades 7 - 9 it is 40 words (Jacobson \& Svensson, 2007).

The intervention group in the primary school increased more than the control group in all tests, especially on sight word reading and pseudoword reading. The results showed that training with reading lists has a good impact on young children's decoding development. At the junior high school, the intervention group increased slightly more than the control group on sight word reading. On the "word recognition" (word chains) test, the increase was almost equal for both the intervention and control groups. However, the intervention group increased significantly more than the control group in pseudoword reading.

\section{Discussion}

The acquisition of letter-speech sound associations is one of the basic requirements for fluent reading acquisition, the failure of which may contribute to reading difficulties. Høien \& Lundberg (2013) state that a very important phase in decoding performance is the phase where a secure connection between grapheme and phoneme plays a central part. Ehri (2005), too, mentions the importance of grapheme phoneme linkage in the "partially alphabetic" phase, where the child can acquire more advanced "sight words". To achieve command of grapheme-phoneme correspondence is of major importance. The method of using reading lists, as in the intervention study, includes phonemes, syllables, pseudowords and whole words in an ascending level of difficulty and complexity. The results showed that this training has a good effect on the decoding development of primary school children. Among junior high school students, the ability to decode pseudowords significantly improved compared with the control group. From the results of this study, where the students in the intervention group improved their pseudoword reading, which is dependent on certain grapheme-phoneme connection, the conclusion can be drawn that they become more confident in their alphabet-phonological decoding. Høien \& Lundberg (2013) argue that the phonological strategy makes great demands on the reader and that clear orthographic identities seem to be closely linked to acquiring good skills at fluent reading. If students in the intervention group were not completely secure in alphabet-phonological reading, i.e. not having fully automatized the grapheme-phoneme connection, they improved from training with reading lists. This, according to Høien and Lundberg, increases the chances for improving orthographic and fluent word decoding. Reading practice with lists containing pseudowords seems to have produced this very effect in the study. In the primary school intervention group, the reading of sight words increased by 14.5 and in junior high school by 9.5 words. Hence, the training with pseudowords and real words may also have influenced the development of orthographic and fluent reading among 
the students.

Torgesen et al. (2001) conclude that the details of the content of the intervention in their study may not be as important in itself as its phonological basis. Reading lists in this study have a phonological basis in sound methodology and essentially bottom-up theories. Gustafson, Ferreira and Rönnberg (2007) noted in their intervention study that children with pronounced phonological difficulties improved their word decoding skills more from phonological than from orthographic training. Another conclusion drawn by Gustafson, Ferreira and Rönnberg (2007) is that pedagogues should choose decoding measures focusing on children's relative weakness rather than on their relative strength. The results of this intervention, containing several students with a poor relationship between grapheme and phoneme, show that when the students practised what they had difficulty in the measures were effective. Students with reading and writing difficulties rarely have time with the overlearning that takes place in the classroom (Høien \& Lundberg, 2013). Following Lundberg \& Herrlin (2003) and Elbro (2004) in stating that it takes time to become a good reader makes "Time on task" an important aspect in this context.

Students with word decoding difficulties need explicit instruction and teacher-led activity (Høien \& Lundberg, 2013; NCLB, 2000). Training with reading lists is a method that works very well in a one-to-one situation, in which the educator can adapt the materials to the students' specific needs as well as provide direct guidance.

\section{Limitations of the Study and Future Research}

With a more extensive time frame and more participants in the study, results had been analyzed on an individual level to a greater extent, individual positions, there would have been interesting to proceed with. The relatively low number of participants in the study made it impossible to establish any general conclusions. A study that examined both spelling development and decoding development, linked to reading lists that would have contributed another dimension of interventions by reading training materials. Also a deeper analysis of each student's decoding difficulties and group they priored to the intervention of various groups (such as dyslexia, "guessing readers" slow decoders) would have been very interesting for a future study.

\section{References}

Egerhag, H. \& Svärd, E. (2011). Intensive Reading Practice-An Intervention Study with Rydaholm Method in 7th Grade. Växjö: Linnaeus University.

Elbro, C. (2004). Läsning och läsundervisning. Reading and Readingin Struction. Stockholm: Liber AB.

Ehri, L. C., Nunes, S. R., Willows, D. M., Schuster, B. V., Yaghoub-Zadeh, Z., \& Shanahan, T. (2001). Phonemic Awareness Instruction Helps Children Learn to Read: Evidence from the National Reading Panel's Meta-Analysis. Reading Research Quarterly, 3, 250. http://dx.doi.org/10.1598/RRQ.36.3.2

Ehri, L. C. (2005). Development of Sight Word Reading: Phases and Findings. In M. J. Snowling, \& C. Hulme (Eds.), The Science of Reading [Electronic Resource]: A Handbook (pp. 135-154). Oxford: Blackwell Publishing.

Fälth, L. (2013). The Use of Interventions for Promoting Reading Development among Struggling Readers. Växjö: Linnaeus University.

Høien, T. \& Lundberg, I. (2013). Dyslexi från teori till praktik. Stockholm: Natur och Kultur.

Jacobson, C. (2001). Word Chains. Stockholm: Psykologiförlaget.

Jacobson, Svensson \& af Trampe. Unpublished Data.

Jönsson, B. (2010). BRAVKOD. Uppsala: JL Utbildning.

Lundberg, I., Frost, J., \& Petersen, O. (1998). Effects of an Extensive Program for Stimulating Phonological Awareness in Preschool Children. Reading Research Quarterly, 23, 264-293.

Lundberg, I., \& Herrlin, K. (2003). God läsutveckling Kartläggning och övningar (Good Reading Skills Identification and Training). Stockholm: Natur och Kultur.

NCLB - National Institute of Child Health and Human Development (2000). Report of the National Reading Panel. Teaching Children to Read: An Evidence-Based Assessment of the Scientific Research Literature on Reading and Its Implications for Reading Instruction. NIH Publication No. 00-4769, Washington DC: US Government Printing Office.

Pettersson, C. E. (2015). Rydaholmsmetoden (The Method of Rydaholm). http://www.rydaholmsmetoden.se/

SBU (2014). Dyslexia in Children and Adolescents-Tests and Interventions. A Systematic Literature Review. 2014 SBU

Report No. 225, Stockholm: Swedish Council on Health Technology Assessment Health Care (SBU). 
Torgesen, J., Alexander, A., Wagner, R., Rashotte, C., Voeller, K., \& Conway, T. (2001). Intensive Remedial Instruction for Children with Severe Reading Disabilities: Immediate and Long-Term Outcomes from Two Instructional Approaches. Journal of Learning Disabilities, 34, 33-78.

Wendick, G. (2015). Wendickmodellen Intensivläsning (The Wendick Model Intensive Training). http://www.wendick.se

Wolff, U. (2011). Effects of a Randomised Reading Intervention Study: An Application of Structural Equation Modelling. Dyslexia, 17, 295-311. http://dx.doi.org/10.1002/dys.438 